\title{
Enhancing Students' Attitude towards Biology through the Integration of Traditional Medicine and 5E's Learning Cycle
}

\author{
Teshager Ali ${ }^{1}$, Aweke Shishigu ${ }^{2}$, Solomon Belay Faris $^{3}$, \& Sutuma Edessa ${ }^{3}$ \\ Addis Ababa University, Ethiopia.
}

\begin{abstract}
The study investigated the effect of integrating traditional medicine (TM) concepts with grade 9th microorganism and disease topics on students' attitude towards biology. The study used a quasiexperimental pretest, posttest non-equivalent group design. two intact classes were selected in Chiro district of Oromia Regional State, Ethiopia. The first class belonged to the treatment group where TM contents are integrated through 5E's learning cycle with the topic Microorganism and Disease and the second was assigned as comparison group learning the same biology unit on Microorganisms and Disease using the usual approach. Biological Attitude Questionnaires (BAQ) was administered for both groups as pre-and post-tests. The findings showed that the integration of TM with the school biology enhanced students' attitude towards biology as compared with teaching the topics without integration.
\end{abstract}

Keywords: traditional medicine, microorganism and disease, 5E's learning cycle, attitude towards biology.

\footnotetext{
${ }^{1} \mathrm{PhD}$ student in the Department of Science and Mathematics Education, Ethiopia. Teshagerali123@gmail.com 2 Assistant Professor in Mathematics Education, Institute of Educational Research (IER), Addis Ababa University, Ethiopia. awekeu@gmail.com

3 Assistant Professor in Biology Education, Department of Science and Mathematics Education, Addis Ababa University, Ethiopia. Solomon.faris@gmail.com

3 Associate Professor in Biology Education, Department of Science and Mathematics Education, Addis Ababa University, Ethiopia. sutuma2002@yahoo.com
} 


\section{Introduction}

The Ethiopian Government has given great emphasis to Science, Technology, Engineering, and Mathematics (STEM) education. Accordingly, a ratio of 70:30 has been advocated, i.e., to enrol $70 \%$ of students in science and technology fields (MoE, 2012). This emphasis on science and technology was designed to help fill the gap for the scarcity of professionals in the construction, industry, and health care sectors. However, these objectives have not been fulfilled due to lack of competency on the part of the graduates in creating jobs and most Ethiopian graduates of STEM remain unemployed. This has caused the development of negative attitudes towards science and technology fields in students thus further aggravating the problem of lack of interest in science education (Mulatie, 2018). Students' attitudes towards science influence their interest to study science. This affects the amount of time and effort they exert on learning/studying science, a factor which ultimately determines their academic successes (Mulatie, 2018).

Research in science education has indicated that positive students' attitude towards science is one of the factors that contributes to meaningful learning of science because students bring significant expectations into classrooms (Alzahrani, 2016). Attitude towards science can be favorable or unfavorable feelings about science as a school subject (Sitotaw \& Tadele, 2016). The study of Attitude as a construct has gained much popularity in science education research as students' attitude towards science can affect their academic performance (Osborne, Simon, \& Collins, 2003).

Studies show that students are not excited by the manner that science is taught in Ethiopian high school classrooms; it does not consider worldview differences nor connect their indigenous knowledge with the school science (Mekuria, et al, 2018,). This disconnect and lack of context negate the development of student's positive attitude towards science subjects. Since science is presented within a Western cultural context without being related to students' everyday life, students' interest, motivation, and enjoyment are often reduced (Hussaini, Foong \& Kamar, 2015). Thus, this study investigated the role of the integration of TM with school biology in enhancing the attitudes of students by applying cultural border crossing (CBC) approach.

There are no extant empirical studies on how the integration of IK TM influenced students' attitude towards biology in Ethiopia and elsewhere. Thus, this is a pioneering study that focused 
on investigating how students' positive attitude towards biology can be enhanced by integrating IK with the school biology using $\mathrm{CBC}$ approach. It starts off with the assumption that the integration of TM with school biology can foster students' participation, interaction, discussion, cooperative learning, and practical activities so that their attitude towards the subject may improve. Applying various teaching-learning methods and relating students to their everyday life is important to enhance positive attitude towards science (Alemu, 2013). The interaction of students with TM concepts as cognitive tool, and with their peers, teachers, and the regular study material may bring a positive change in their attitudes towards biology (Alemu, 2013).

Ethiopia's Education and Training Policy (ETP) encourages teachers to employ a constructivist and learner centered approach to teach science (ETP, 1994). This approach aimed to increase students' motivation and engagement. It helps them participate actively in constructing meaning out of their learning experience by connecting what they are learning with what they already know. TM serving as prior knowledge when integrated with school biology should thus enhance students' understanding of the subject and improve their attitude towards it.

How students perceive the learning environment can affect their attitudes towards biology. If the classroom environment addresses worldview differences through bridging school biology with indigenous knowledge, students may develop a positive attitude towards it. The study undertaken by Cimer indicated that teaching biology in a manner that connects the topics with students' everyday lifeworld helps them develop a positive attitude (Cimer, 2012). Research in South Africa also confirmed that motivation and participation of students increases when IK practices are integrated into school science (Cameron, 2007; Manzini, 2006).

This study investigated whether the integration of IK with school biology plays any role in enhancing students' positive attitude towards the subject. The study employed cultural border crossing $(\mathrm{CBC})$ as a framework for and bridge to biology education: students' IK was the bridge, prior knowledge of TM and the worldview it embedded, which was linked with school biology. The approach aimed at facilitating a smooth border crossing between IK and school biology to facilitate students developing a positive attitude towards the subject.

\section{Methodology}


To achieve the goal of the study, a quasi-experimental pre-test, post-test non-equivalent control group design was employed. This design helps to control various extraneous variables. A total of 177 students ( 88 in the treatment and 89 in the comparison group) participated as intact classes from two high schools in Chiro district, Oromia Regional State, Ethiopia. The two groups had been taught the same topics (microorganism and disease) as presented in a grade 9th biology textbook. The teacher who taught the experimental group took a three-day training on how to integrate the indigenous knowledge on TM with the biology topics using the 5E's instructional model. The comparison group were taught the same biology topics without integrating the IK but using the usual approach. The intervention lasted for six weeks after which the questionnaires were administered to both groups as post-test.

The Biology Attitude Questionnaire (BAQ) consisting of seven components was used as instruments of data collection. The reliability of the BAQ using Cronbach's Alpha was 0.91. The tool was also reviewed by a panel of experts in the area to ensure face and content validity. Our use of theoretical background and literature review serves to address construct validity. To ensure that the treatment group received all the aspects stipulated in the design, the procedures followed within the 5E learning cycle were as follow:

○ During the Engagement stage students were given scenarios depicting a particular disease together with how TM healers diagnose the same ailment by prescribing a certain type of TM with a specified dosage to take apply at specific time interval. This was to get the students engaged.

- During the second, explore stage, students were given points of discussion to discuss in groups and to debate. Here they manipulated specific medicinal plants and discussed which part is used as medicine, how drugs are extracted, and how dosage is regulated including how the drug is administered into the body. This helped students to identify the strong and weak sides of the TM practices compared with modern medicines. This helped them to discuss the drawbacks of TMs and how to improvements might be made. The teacher acts as cultural brokers and facilitates discussion as he went round each group.

- In the explain stage, the students explained what was discussed in the explore stage. The teacher presented the science topic about a specific microorganism, its modes of 
transmission, and measures to control the disease and tried to make a link with the traditional perception about diseases and their traditional treatment options.

○ In the elaborate stage the teacher allowed students to reflect on their understanding of how medicinal plants are important in curing particular diseases and compared the mechanism of control with the biomedicine.

- Finally, students' understanding of the biological concepts was evaluated.

\section{Results}

\section{Descriptive Data Analysis and Interpretations}

A preliminary analysis and interpretation were made to understand the nature of data set obtained from both the pre-tests- and post-tests to check assumptions and make ready for the appropriate inferential statistical tools. Descriptive statistics were generated to examine the extent to which the assumptions of the statistics were satisfied. The statistical assumptions explain when it is not justifiable to perform a specific inferential statistical test. The type of inferential statistical tool planned to compare the treatment and comparison groups based on their mean score on the BAQ test scores was independent samples t-test. However, this statistical tool is used based on some basic statistical assumptions which include: (1) independent measurement, (2) the dependent variables should be normally distributed in each group and (3) there are equal variance (homogeneity of variance) of the dependent variable across the groups (Pallant, 2005).

Independent measurement was assured in the research design by selecting intact classes of the respective schools and each set of participants is tested under only one treatment condition. In addition, each group was subjected to same questionnaire at same time. The normal distribution was checked using skewness. Levene test was also used for further analysis of the homogeneity of variances of the data sets. 
Table 1. Descriptive statistics summary related to the scores on BAQPRE and BAQPOST for the treatment and comparison groups

\begin{tabular}{|c|c|c|c|c|c|c|c|c|}
\hline Group & Variable & $\mathrm{N}$ & Mean & $\mathrm{SD}$ & Min. & Max. & Skewness & Kurtosis \\
\hline \multirow[t]{3}{*}{ Treatment } & BAQPRE & 88 & 157.56 & 16.49 & 117 & 185 & -.382 & -.512 \\
\hline & BAQPOST & 88 & 185.50 & 16.72 & 153.00 & 227.00 & .306 & -.400 \\
\hline & BAQPRE & 89 & 153.56 & 14.02 & 126 & 187 & .027 & -.678 \\
\hline Comparison & BAQPOST & 89 & 170.40 & 12.97 & 143 & 212 & .237 & .162 \\
\hline
\end{tabular}

BAQPRE: Biology Attitude Questionnaire Pre-test

BAQPOST: Biology Attitude Questionnaire Post-test

Descriptive statistics were generated using exploratory data analysis technique to get the basic information on mean score, variation (the range of scores) and normality of the data sets obtained from pre-test and post-test. The mean score of the treatment group on the BAQPRE $(M=157.56, S D=16.72)$ was almost equal to the mean score of the comparison group $(M=153.56$, $\mathrm{SD}=14.02$ ). These results revealed that the two groups were having almost equal level of attitude towards biology before the intervention. Thus, any difference which would occur in the post-test results between the treatment and the comparison groups would be accounted for by the effect of the intervention. After the intervention had been carried out, a BAQ post-test covering the planned topics was given for the two groups immediately after. As it can be noticed in table 1, mean score of the treatment group on BAQPOST $(\mathrm{M}=185.50, \mathrm{SD}=16.72)$ was greater than the mean score of the comparison group ( $\mathrm{M}=170.40, \mathrm{SD}=12.97)$. However, it is too early to give a conclusive idea based on these results without undergoing inferential statistics.

In addition, results obtained from the exploratory data analysis outputs provided in Table1 were used to check some of the statistical assumptions for the independent samples t-test. The main statistical assumption that was used to check from these outputs was normality of the dependent variables in each group. The skewness of the variables was used for checking normality. From the outputs provided in Table 1, it can be seen that all of these variables have skewness values between -1 and 1 . These results show that the variables in each group were at least normally distributed; the BAQPRE and BAQPOST at least approximately normally distributed in each 
group and were more like scale variables. Hence, it was justifiable to use the independent samples t-test to compare means of the two groups on these variables.

\section{Inferential statistics and Interpretations}

Table 2. Independent Samples t-test analysis to compare the Treatment and Comparison Groups on BAQPRE

\begin{tabular}{lllllllll}
\hline Variable & Group & $\mathrm{N}$ & $\mathrm{M}$ & $S D$ & $T$ & $d f$ & $d$ & $P$ \\
\hline BAQPRE & Treatment & 88 & 157.56 & 16.49 & 1.74 & 175 & .26 & .084 \\
& Comparison & 89 & 153.56 & 14.02 & & & & \\
\hline
\end{tabular}

The above table shows a pretest on attitude scale to determine base line equivalence of the two groups. An independent samples t-test was computed to determine if a difference existed in the attitude towards biology between the treatment and comparison groups. The result shows that there was non-significant mean difference in BAQPRE scores between the treatment and comparison groups $(\mathrm{t}(175)=1.74, \mathrm{P}>.05, \mathrm{~d}=.26)$. This indicates that the two groups were in the same status with regard to their attitude towards biology before the intervention. Therefore, any difference after the intervention can be attributed to the presence of the intervention provided that other confounding variables are controlled.

\section{Attitudes of Students towards Biology}

Ho-2: There is no significant difference in the mean scores of students' attitude towards biology taught by integrating traditional medicine contents with school biology using the 5E's learning cycle model compared with those taught the biology topic using the usual approach.

Table 3. Independent Samples t-test analysis to compare the Treatment and Comparison Groups on the BAQPOST.

\begin{tabular}{cccccccc}
\hline Group & $\mathrm{N}$ & $M$ & $S D$ & $t$ & $d f$ & $d$ & $P$ \\
\hline Treatment & 88 & 185.5 & 16.72 & 6.71 & 163.94 & 1.02 & .000 \\
Comparison & 89 & 170.40 & 12.97 & & & & \\
\hline
\end{tabular}


An independent t-test was conducted to compare students' attitude towards biology post-test scores for the treatment and comparison groups. The value of Levene's test of equality of variance was significant $(\mathrm{P}<.05)$ and hence the statistics for equal variance not assumed was considered. The result displayed in table 3, revealed that the mean score of the treatment group ( $M=185.5$, $\mathrm{SD}=16.72)$ is significantly greater than the mean score of the comparison group $(\mathrm{t}(163.94)=6.71$, $P<.05, d=1.02)$. This was manifested in the effect size of $d=1.02$, which was larger than typical (Cohen, 1988). This shows the treatment group possess better attitude towards biology than the comparison group after the intervention. The integration of TM with school biology was therefore effective in learning biology topics than otherwise. Since the treatment group was not different significantly from the comparison group on the BAQPRE, the implication is that the two groups were in the same status regarding their BAQPRE before the intervention. Therefore, the difference can be ascribed to the integration of IK with school biology. Hence, we can conclude that the null hypothesis of non-significance difference in the mean scores of the two groups regarding attitude variable was rejected and the alternative hypothesis that there is significant difference in the mean scores between the treatment and the comparison groups on attitude towards biology was accepted. This indicates the integration of IK with biology topics improves students' attitudes towards biology. The components of $\mathrm{BAQ}$ is presented in table 4 to see variability withing the construct.

Table 4. Descriptive Statistic Summary of the components of Biology Attitude pre-test scores for the Treatment and Comparison Groups

\begin{tabular}{ccccccccc}
\hline Group & Variable & $\mathrm{N}$ & Mean & SD & Min & Max & Skewness & Kurtosis \\
\hline \multirow{2}{*}{ Treatment } & UPRE & 88 & 25.27 & 4.98 & 15 & 39 & .192 & -.061 \\
& MPPRE & 88 & 24.91 & 4.42 & 14 & 39 & .242 & .328 \\
& IPRE & 88 & 37.15 & 6.18 & 22 & 49 & -.343 & -.622 \\
& DPRE & 88 & 19.14 & 3.71 & 11 & 28 & -.196 & .099 \\
& TSPRE & 88 & 19.28 & 3.46 & 10 & 27 & .075 & -.051 \\
& LAPRE & 88 & 11.95 & 2.55 & 5 & 20 & .188 & -.802 \\
& FCPRE & 88 & 12.57 & 2.95 & 6 & 20 & -.026 & -.352 \\
\hline
\end{tabular}




\begin{tabular}{ccccccccc}
\hline \multirow{5}{*}{ Comparison } & UPRE & 89 & 23.74 & 3.95 & 13 & 34 & -.335 & -.114 \\
& MPRE & 89 & 26.33 & 4.05 & 15 & 38 & .141 & .353 \\
& IPRE & 89 & 37.45 & 5.58 & 26 & 51 & -.154 & -.559 \\
& DPRE & 89 & 18.35 & 2.87 & 11 & 24 & .033 & -.583 \\
& TSPRE & 89 & 17.69 & 3.12 & 11 & 25 & .132 & -.411 \\
& LAPRE & 89 & 12.60 & 2.76 & 6 & 19 & -.196 & -.452 \\
FCPRE & 89 & 11.02 & 2.36 & 5 & 17 & .063 & .141 \\
\hline
\end{tabular}

UPRE: Usefulness Pretest

MPRE: Motivation Pretest

IPRE; Interest Pretest
TSPRE: Teacher Support Pretest

LAPRE: Laboratory Activity Pretest

FCPRE: Future Career Pretest

DPRE: Difficulty Pretest

Descriptive statistics were generated using exploratory data analysis technique to get the basic information on mean scores, variation (the range of scores between the maximum and minimum) and normality of data sets obtained from attitude component pretest scores. Table 4 provides the descriptive statistic summary related to the UPRE, MPRE, IPRE, DPRE, TSPRE, LAPRE and FCPRE for the treatment and comparison groups. As can be observed from the table, the means scores on the attitude components between the treatment and comparison groups showed very slight variations on these variables before the intervention. Students in the treatment group had more positive attitude towards the usefulness of biology $(\mathrm{M}=25.27, \mathrm{SD}=4.98)$ than the comparison group $(\mathrm{M}=23.74, \mathrm{SD}=3.95)$. The comparison group demonstrated somewhat greater motivation $(\mathrm{M}=26.33, \mathrm{SD}=4.05)$ than the treatment group $(\mathrm{M}=24.91, \mathrm{SD}=4.42)$ before intervention. The treatment group had the same interest $(\mathrm{M}=37.15, \mathrm{SD}=6.18)$ with the comparison group $(\mathrm{M}=37.45, \mathrm{SD}=5.58)$ before the intervention. The treatment group $(\mathrm{M}=$ $19.14, \mathrm{SD}=3.71)$ feel difficulty in biology learning equivalent to the comparison group $(\mathrm{M}=$ $18.35, \mathrm{SD}=2.87)$. The consideration of teacher's support for biology learning was slightly greater 
for the treatment group $(\mathrm{M}=19.28, \mathrm{SD}=3.46)$ than the comparison group $(\mathrm{M}=17.69, \mathrm{SD}=3.12)$. The attitude of students towards learning biology supported with laboratory activity was almost at the same status $(\mathrm{M}=11.95, \mathrm{SD}=2.55)$ with the comparison group $(\mathrm{M}=12.60, \mathrm{SD}=2.76)$. The perceptions of the students in the treatment group on the contribution of biology for future career was slightly greater $(\mathrm{M}=12.57, \mathrm{SD}=2.95)$ than the comparison group $(\mathrm{M}=11.02, \mathrm{SD}=2.36)$.

Based on these results, there were viable variations on some of the attitude components before the intervention. But these pre-existing variations can be treated as natural since there was no random assignment of students in the two groups. However, we have statistical mechanisms that can be used to control the pre-existing variation between the groups on these variables. In addition to these values, results obtained from the descriptive data analysis outputs provided in Table 4 were used to check for some of the statistical assumptions for the independent samples ttest. The skewness of the variables was used for checking normality. The result shows that all the attitude components had skewness values between -1 and 1 . These results tell us that the variables in each group were at least normally distributed. Thus, it can be assured that attitude components were at least approximately normally distributed in each of the groups, and they were more like scale variables. Hence, it was justifiable to use the independent samples t-test to compare the means of the two groups on all of the data obtained from the pretest scores of the attitude components.

Table 5. Independent Samples t-test analysis summary to compare the Treatment and Comparison Groups on the pretest.

\begin{tabular}{lllllllll}
\hline Variable & Group & $\mathrm{N}$ & Mean & $S D$ & $t$ & $d f$ & $P$ & $d$ \\
\hline UPRE & Treatment & 88 & 25.27 & 4.98 & 2.268 & 175 & .025 & .34 \\
& Comparison & 89 & 23.74 & 3.95 & & & & \\
\hline \multirow{2}{*}{ MPRE } & Treatment & 88 & 24.91 & 4.42 & -2.224 & 175 & .027 & .34 \\
& Comparison & 89 & 26.33 & 4.05 & & & & \\
\hline \multirow{2}{*}{ IPRE } & Treatment & 88 & 37.15 & 6.18 & -.341 & 175 & .733 & .05 \\
& Comparison & 89 & 37.45 & 5.58 & & & & \\
\hline
\end{tabular}




\begin{tabular}{lllllllll}
\hline DPRE & Treatment & 88 & 19.14 & 3.71 & 1.581 & 175 & .116 & .24 \\
& Comparison & 89 & 18.35 & 2.87 & & & & \\
\hline TSPRE & Treatment & 88 & 19.28 & 3.46 & 3.230 & 175 & .001 & .48 \\
& Comparison & 89 & 17.69 & 3.12 & & & & \\
\hline LAPRE & Treatment & 88 & 11.95 & 2.55 & -1.60 & 175 & .111 & .24 \\
& Comparison & 89 & 12.60 & 2.76 & & & & \\
\hline FCPRE & Treatment & 88 & 12.57 & 2.95 & 3.846 & 166.130 & .000 & .25 \\
& Comparison & 89 & 11.02 & 2.36 & & & & \\
\hline
\end{tabular}

An independent sample t-test presented in table 5 shows the difference obtained on each of the attitude component before the intervention. The result shows that there were non-significant mean differences on the IPRE between the treatment group $(\mathrm{t}(175)=-0.341, \mathrm{P}>0.05)$. Similarly, there was no statistically significant mean difference on the DPRE between the treatment group $(n=88$, $\mathrm{M}=19.14, \mathrm{SD}=3.71)$ and the comparison group $(\mathrm{n}=89, \mathrm{M}=18.35, \mathrm{SD}=2.87, \mathrm{t}(175)=1.581$, $\mathrm{P}>0.05)$. These results revealed that the treatment and comparison groups were in the same status with respect to the IPRE and DPRE.

The result also shows that there was non-significant difference on the LAPRE between the treatment group and the comparison group $(\mathrm{t}(175)=-1.60, \mathrm{p}>0.05, \mathrm{~d}=0.24)$. But there was a significant mean difference in the UPRE favoring the treatment group $(\mathrm{t}(175)=2.268, \mathrm{P}<0.05$, $d=0.34)$. The mean difference of MPRE $(t(175)=-2.224, P<0.05, d=0.34)$, was significant favoring the comparison group but the mean difference of TSPRE ( $\mathrm{t}(175)=3.230, \mathrm{P}<.05, \mathrm{~d}=$ $.48)$, FCPRE $(\mathrm{t}(166.130)=3.846, \mathrm{P}<.001, \mathrm{~d}=.25)$ is found to be statistically significant the reason the treatment group showed a better result. Thus, the treatment group demonstrated favorable attitude than the comparison group on these three attitude components, namely, Usefulness, Teacher Support, and Future Career and the comparison group is better in motivation component. Students' variations on these variables before the intervention is no cause for panic since such variation on the pretest can be managed by undergoing further statistical analysis (ANOVA), while comparing the groups on post test scores for the variables. Thus, ANCOVA was 
used to compare the mean difference of the two groups on the UPOST, MPOST, TSPOST, and FCPOST using the UPRE, MPRE, TSPRE, and FCPRE as covariates.

Table 6. Descriptive Statistic Summary of the Components of Biology Attitude Post-Test Scores for the Treatment and Comparison Groups.

\begin{tabular}{lllllllll}
\hline Group & Variables & $\mathrm{N}$ & Mean & $\mathrm{SD}$ & Min & Max & Skewness & Kurtosis \\
\hline \multirow{5}{*}{ Treatment } & UPOST & 88 & 31.14 & 3.49 & 23 & 38 & -.239 & -.446 \\
& MPOST & 88 & 28.78 & 4.45 & 17 & 38 & .025 & -.248 \\
& IPOST & 88 & 42.03 & 6.03 & 31 & 55 & .356 & -.66 \\
& DPOST & 88 & 24.72 & 3.55 & 17 & 30 & -.292 & -.851 \\
& TSPOST & 88 & 21.88 & 2.86 & 16 & 30 & .135 & -.171 \\
& LAPOST & 88 & 15.94 & 2.49 & 7 & 20 & -.612 & -.651 \\
& FCPOST & 88 & 14.76 & 2.91 & 6 & 20 & -.612 & .253 \\
\hline \multirow{5}{*}{ Comparison } & MPOST & 89 & 28.63 & 3.17 & 22 & 36 & .204 & -.519 \\
& MPOST & 89 & 25.93 & 4.36 & 17 & 38 & .177 & -.04 \\
& IPOST & 89 & 38.55 & 5.30 & 29 & 51 & .334 & -.316 \\
& DPOST & 89 & 21.38 & 3.85 & 13 & 30 & .106 & -.663 \\
& TSPOST & 89 & 21.07 & 3.36 & 14 & 28 & -.110 & .424 \\
& LAPOST & 89 & 15.10 & 2.51 & 9 & 20 & -.192 & -.103 \\
FCPOST & 89 & 14.06 & 2.98 & 6 & 18 & -.639 & -.293 \\
\hline
\end{tabular}

Table-6 provides the descriptive statistic summary related to the UPOST, MPOST, IPOST, DPOST, TSPOST, LAPOST, and FCPOST for the treatment and comparison groups. As it can be observed from the mean scores on attitude components between the treatment and comparison groups, we can see big variation on most of the variables in favor of the treatment group and the variation was nearly equal on some of the other variables. The treatment group demonstrated a positive attitude towards the usefulness of biology $(\mathrm{M}=31.14, \mathrm{SD}=3.49)$ than the comparison 
group $(\mathrm{M}=28.63, \mathrm{SD}=3.17)$. Students in the treatment group are highly motivated in learning biology $(M=28.78, S D=4.45)$ than the students in the comparison group $(M=25.93, S D=4.36)$. The treatment group was more interested $(\mathrm{M}=42.03, \mathrm{SD}=6.03)$ than the comparison group $(\mathrm{M}=38.55$, $\mathrm{SD}=5.30)$. Likewise, the comparison group showed some difficulty in learning biology $(\mathrm{M}=21.38$, $\mathrm{SD}=3.85)$ than the treatment group $(\mathrm{M}=24.72, \mathrm{SD}=3.55)$. The attitude of the students in the treatment group towards teacher's support for effective learning of biology $(\mathrm{M}=21.88, \mathrm{SD}=2.86)$ is nearly equal to the comparison group $(\mathrm{M}=21.07, \mathrm{SD}=3.36)$.

The attitude of the treatment group in learning biology in the laboratory activity $(M=15.94$, $\mathrm{SD}=2.49)$ was nearly equal to the comparison group $(\mathrm{M}=15.10, \mathrm{SD}=2.51)$. Similarly, the attitude of students in the treatment group towards the importance of learning biology for future career $(\mathrm{M}=14.76, \mathrm{SD}=2.91)$ was nearly equal to the comparison group $(\mathrm{M}=14.06, \mathrm{SD}=2.98)$. These result shows that the comparison and treatment groups are situated at different positions regarding most of the attitude components towards biology after the intervention. The mean scores of the two groups on the IPOST showed variation in favor of the treatment group.

In addition to these, the results obtained from the exploratory data analysis provided in Table 6 were used to check for some of the statistical assumptions for the independent samples ttest. The main statistical assumption that was used to check from these outputs was normality of the dependent variables in each group. All of the variables in the attitude components had skewness values between -1 and 1 . Thus, it is clear that the attitude components were at least approximately normally distributed for both groups and they were more like scale variables. Hence, it was justifiable to use the independent samples t-test to compare statistically the mean difference of the two groups on all of the data obtained from the post-test scores of the attitude components.

Table 7. Independent Samples t-test Analysis Summary to compare the Treatment and Comparison Groups on the Attitude Components of IPOST, DPOST and LAPOST

\begin{tabular}{lllllllll} 
Variable & Group & $\mathrm{N}$ & $M$ & $S D$ & $t$ & $d f$ & $P$ & $d$ \\
\hline \multirow{2}{*}{ IPOST } & Treatment & 88 & 42.03 & 6.03 & 4.082 & 175 & .000 & .61 \\
& Comparison & 89 & 38.55 & 5.30 & & & & \\
\hline \multirow{2}{*}{ DPOST } & Treatment & 88 & 24.72 & 3.55 & 5.987 & 175 & .000 & .90 \\
& Comparison & 89 & 21.38 & 3.85 & & & & \\
\hline
\end{tabular}




\begin{tabular}{lllllllll}
\hline LAPOST & Treatment & 88 & 15.94 & 2.49 & .026 & 175 & .026 & .34 \\
& Comparison & 89 & 15.10 & 2.51 & & & & \\
\hline
\end{tabular}

Table 7 provides the summary of independent samples t-test on IPOST, DPOST, and LAPOST for the treatment and comparison groups. The result of the study shows that there was statistically significant mean differences on the IPOST between the treatment group $(\mathrm{t}(175)=4.082, \mathrm{P}<0.05)$. In addition to the information on the statistical significance outcome, the effect size can also provide information on the magnitude of the difference between levels of the independent variable with respect to the dependent variable. The effect size for the IPOST was found to be $d=.61$, which was larger than typical. This result revealed the treatment group performed better than the comparison group. This shows that the integration of TM with school biology was more effective than learning biology topics without integrating TM in fostering the interest of the students in biology. Similarly, there was statistically significant mean difference on the DPOST (t (175) $=5.987, \mathrm{P}<0.05$ ). This result was manifested in the associated effect size of $\mathrm{d}=.90$, which is larger than typical according to Cohen (1988). This result revealed that the integration of IK with school biology highly minimized the students' perception towards the difficulty of biology. Likewise, students in the treatment group preferred to learn biology supported by the laboratory activity $(\mathrm{t}(175)=2.242, \mathrm{P}<0.05, \mathrm{~d}=.34)$.

To compare the two groups on the remaining attitude components (UPOST, MPOST, TSPOST and FCPOST); analysis of covariance (ANCOVA) was used considering the UPRE, MPRE, TSPRE and FCPRE as covariates. ANCOVA typically provides a means of statistically controlling for the effect of continuous or scale covariate on the independent variable in predicting the dependent variable. To eliminate the bias of the treatment effect that results from the measurement error inherent in the pre-test when studying non-equivalent groups, using a reliability corrected ANCOVA model to adjust the pretest for measurement error is essential. The ANCOVA has statistical assumptions that increase the validity of the results obtained from it. These are Independent measurements, normal distribution, homogeneity of variances and homogeneity of regression slopes. The assumption of independent measurements was addressed during the research design and data collection stage. As it is displayed in Table 6, the normality and 
homogeneity of variances of UPOST, MPOST, TSPOST and FCPOST were checked using skewness value, Kurtosis and Levene test. The assumption of homogeneity of regression slopes is one of the most important assumptions and it can be checked with an F test on the interaction of the independent variables with the covariate. If the $\mathrm{F}$ test is significant, then this assumption has been violated. In the interaction of the pre-tests and the post-tests of the four cases, the F test obtained was non-significant. Hence, the assumption of homogeneity of regression slopes was not violated for Group*UPRE ( $\mathrm{P}=.463)$, Group*MPRE $(\mathrm{P}=.246)$, Group*TSPRE $(\mathrm{P}=.751)$ and Group*FCPRE ( $\mathrm{P}=.925)$. Thus, these data sets were qualified for using the ANCOVA.

Table 8. Analysis of Covariance for UPOST, MPOST, TSPOST, and FCPRE as a Function of the Groups, using the UPRE, MPRE, TSPRE, and FCPRE taken as a Covariate

\begin{tabular}{lllllll}
\hline Source & SS & D $f$ & $M S$ & $F$ & $P$ & $E^{2} a^{2}$ \\
\hline UPRE & 12.996 & 1 & 12.996 & 1.170 & .281 & .007 \\
Group & 250.546 & 1 & 250.546 & 22.563 & .000 & .115 \\
Error & 1932.132 & 174 & 11.104 & & & \\
\hline MPRE & 90.470 & 1 & 90.470 & 4.770 & .030 & .027 \\
Group & 411.379 & 1 & 411.379 & 21.691 & .000 & .111 \\
Error & 3300.023 & 174 & 18.966 & & & \\
\hline TSPRE & 251.452 & 1 & 251.452 & 8.121 & .005 & .045 \\
Group & 555.698 & 1 & 555.698 & 17.947 & .000 & .094 \\
Error & 5387.468 & 174 & 30.962 & & & \\
\hline FCPRE & 189.19 & 1 & 189.19 & 24.80 & .000 & .125 \\
Group & .435 & 1 & .435 & .057 & .812 & - \\
Error & 1327.52 & 174 & & & & \\
\hline
\end{tabular}


The results displayed in Table 8 indicates that after controlling for the UPRE, MPRE, TSPRE and FCPRE, there were significant differences between the treatment and comparison groups on the $\operatorname{UPOST}(\mathrm{F}(1,174)=22.563, \mathrm{P}<0.05), \operatorname{MPOST}(\mathrm{F}(1,174)=21.691, \mathrm{P}<0.05)$ and on the TSPOST $(\mathrm{F}(1,174)=17.947, \mathrm{P}<0.05)$. To the contrary, there was non-significant difference on the FCPOST between the treatment and comparison groups $(\mathrm{F}(1,174)=.057, \mathrm{P}>0.05)$. As is evident from Table $8,11.5 \%$ of the variances on the UPOST, $11.1 \%$ of the variances in the MPOST, and 9.4\% of the variances in TSPOST between the treatment and comparison groups were explained by the independent variable being considered. Therefore, the integration of TM with school biology was effective than learning biology without integrating TM in influencing these attitude components towards biology in favor of the treatment group except FCPOST. This shows that the integration of TM with school biology significantly improved attitudes of students towards biology.

The integration of TM with school biology improved the general attitudes of students towards biology. Therefore, the null hypothesis of no significance difference was rejected and the alternative hypothesis of there is significance difference between the two groups in terms of the six attitude components except FC is accepted in favor of the treatment group. Hence, in terms of influencing attitudes of students towards biology, the integration of TM with the school biology played a very important role.

\section{Discussions of the Findings}

Evaluation of the overall attitudes of students between the treatment and comparison groups showed that both groups have positive attitudes towards biology before and after the intervention. However, comparison of the two groups based on post-test mean scores indicated that students in the treatment group showed a more positive attitude towards biology than the comparison group.

The analysis of data showed significant mean difference between the two groups when post-BAQ responses were compared. When the group that received instructions based on the integration of TM with school biology was compared with the group that received instructions without integration of TM, the result was in favor of the treatment group. This indicated that integration of TM with school biology was better in enhancing a positive attitude towards biology. If students understand the link between what they learn at school and their everyday life 
experiences, they can understand its relevance. The result of the study shows that understanding the relevance of what students learn helped them develop a positive interest in learning biology which is consistent with the findings of (Zinyeka, 2014; Erinosho, 2013). Moreover, integrating IK with school biology helped students to understand the usefulness of biology to their life, result that is in line with that of (Alemu, 2013). research by Erinosho also confirmed that through integration of indigenous knowledge into the subject, students can understand the usefulness of biology which in turn triggers their interest and motivation to enhance their attitude (Erinosho, 2013).

Krogh and Thomsen (2005) applied the concept of cultural border crossing in research and found it as key predictor of attitudes towards science. Research showed that students in nonWestern countries faced difficulties in crossing cultural borders while learning science (Webb, 2014). These difficulties in crossing cultural borders are barriers to positive attitude of students towards science. To alleviate such problems the IK of the community has to be integrated with school biology to facilitate border crossing. When students crossed cultural borders smoothly, they can understand biological concepts which in turn can improve students' attitude towards biology. The assumption is that the integration of IK with the school biology can foster students' participation, interaction, discussion, cooperative learning, and practical activities which altogether contribute to improve their attitude towards the subject. Using a diversity of teachinglearning methods and involving students in student-centered learning by drawing on and validating their relevant prior knowledge is important to improve their attitude towards science (Alemu, 2013). Manganye (1994) referenced a study conducted in United Kingdom that showed that students' experience and prior knowledge influence their attitude towards science. This supports the position that integrating students' IK with school biology as their everyday life experience and prior knowledge would play an important role in increasing the usefulness of biology and in improving attitude. On the other hand, low interest in learning biology could be due to lack of relevance of biology to student's everyday life, the alienation of biology from the society, and the prevalence of isolated scientific facts in the teaching process (Alemu, 2013).

According to several studies, students' attitudes towards science can also hinder their career choices (Alemu, 2013; Manganye, 1994; Nasr \& Soltani, 2011). The above ideas indicated 
that attitude of students towards science/biology can determine their job preferences. This means that when students develop positive attitude towards science/biology, they are likely to choose science/biology related careers. Thus, among the factors which need to be considered in determining job preferences, students' attitude toward science is worth mentioning. Furthermore, it was found that the way science is taught by relating the topics to students' everyday life contributed to enhancing attitudes towards biology.

\section{Conclusions and Recommendation.}

Integration of IK with school biology facilitated smooth border crossing for the students by creating a favorable classroom environment. Smooth border crossing could be a factor that affects students' attitude towards the subject. This was because favorable learning environment and students' involvement to cross cultural borders between the two forms of knowledge has an important influence upon student attitudes toward biology. This approach has the potential to motivate students to engage in meaningful learning. The integration of indigenous knowledge into science curriculum is effective in improving students' attitude towards biology. Additionally, as indigenous knowledge has science embedded in it, it provides solutions to many real-life problems.

Although there are several qualitative studies concerning the integration of IK into science curriculum, there is scarcity of quantitative data regarding the role of indigenous knowledge in improving the attitude of students towards biology/science. Hence, we hope that this article can provide useful insights concerning integration of indigenous knowledge with school biology to improve students' positive attitude towards biology. Finally, it is recommended to integrate IK with science subjects as it enhances students' attitude towards the subject and can play a role for understanding the concepts under study. We also like to recommend that future research might focus on assessing the challenges of integrating IK with science subjects in different cultural settings.

\section{Author Contribution}

- $\quad$ Shager Ali was responsible for writing the draft background and literature review. He was also involved with field data collection and data analysis.

- Aweke Shishigu was responsible for writing the research report and for reviewing the entire section for completeness and consistency. 
- Solomon Belay Faris was responsible for writing the research report and for reviewing the entire section for completeness and consistency

- $\quad$ Sutuma Edessa was responsible for writing the research report and for reviewing the entire section for completeness and consistency

\section{References}

Alemu, Y. (2013). Students' attitude towards natural science in Debre Markos Town Primary Schools. International journal of technology enhancements and emerging engineering research, 118(2).

Alzahrani, R. (2016). Correlations between Introductory Students' Attitudes About Physics and Conceptual Understanding.

Cameron, A. (2007). Cultural and Religious Barriers to Learning in Basic Astronomy: A South African Study. Unpublished PhD, University of the Witwatersrand, Johannesburg.

Cimer, A. (2012). What makes biology learning difficult and effective: Students' views. Educational Research and Reviews, 7(3), 61.

Cohen, J. (1988). Statistical power analysis for the behavioural sciences, 2nd edn.(Hillsdale, NJ: L. Erlbaum Associates).

Education, T. G. E., \& Policy, T. (1994). Federal Democratic Republic Government of Ethiopia. Addis Ababa, 86.

Erinosho, S. Y. (2013). Integrating indigenous science with school science for enhanced learning: A Nigerian example. International Journal for cross-Disciplinary Subjects in education (IJCDSE), 4(2), 1137-1143.

Hussaini, I., Foong, L. M., \& Kamar, Y. (2015). Attitudes of Secondary School Students towards Biology as a School Subject in Birninkebbi Metropolis, Nigeria. International Journal of Research \& Review, 2(10), 596-600.

Krogh, L. B., \& Thomsen, P. V. (2005). Studying students' attitudes towards science from a cultural perspective but with a quantitative methodology: Border crossing into the physics classroom. International Journal of Science Education, 27(3), 281-302. 
Manganye, H. T. (1994). Factors influencing adolescents' attitude towards biology in Gazankulu (Unpublished Doctoral dissertation).

Manzini, S. T. (2006). Report on the implementation of an African socio-cultural approach to science teaching: Application of the collateral learning theory. Proceedings of 12th International Organisation for Science and Technology Education, Symposium, Park Royal Hotel, Penang, Malaysia pp. 636-643.

Mekuria, Y. S., Alemu, S. D., \& Tadesse, H. (2018). Analysis of Students' Commitment and Attitude towards Mathematics in Secondary School of Dega Woreda, Oromia National Regional State, Ethiopia. Humaniora, 9(2), 187-197.

MoE. F. D. R. E. (2012). Education Statistics Annual Abstract. Addis Ababa: Ethiopian Federal Ministry of Education.

Mulatie, M. (2018). Attitude of Junior and Secondary School Students towards Basic Science Subjects in North Gondar, Ethiopia. The Ethiopian Renaissance Journal of Social Science and Humanities, 5(1), 44-52.

Nasr, A. R., \& Soltani, A. K. (2011). Attitude towards biology and its effects on student's achievement. International Journal of Biology, 3(4), 100.

Osborne, J., Simon, S., \& Collins, S. (2003). Attitudes towards science: A review of the literature and its implications. International journal of science education, 25(9), 10491079.

Pallant, J. (2005). Chapter 11, Correlation. SPSS Survival Manual: A step by step guide to data analysis using SPSS for Windows.

Sitotaw, B., \& Tadele, K. (2016). Student Attitude toward Physics in Primary and Secondary Schools of Dire Dawa City Administration, Ethiopia. World Journal of Educational Research and Reviews, 2(2), 014-021.

Webb, P. (2014). Xhosa indigenous knowledge: Stakeholder awareness, value and choice. International Journal of Science and Mathematics Education, 11, 89-110.

Zinyeka, G. (2014). The epistemological basis of indigenous knowledge systems in science education (Doctoral dissertation, University of Pretoria). 